\title{
Identification of Perspective Transborder Clusters of Russia and Kazakhstan
}

\author{
Galina. A. Khmeleva \\ Ludmila V. Orlova \\ Olga A. Bulavko \\ Klim O. Kostromin
}

Sayra K. Umerbaeva

Doi:10.5901/mjss.2015.v6n4s2p302

\begin{abstract}
Under conditions of globalization and political transformation of the world, a further economic, political, and cultural integration of Russia and Kazakhstan is expected. Most of the Russia's population associate the further development of the country with the Eurasian economic community. This is not by accident. In 2012, a single economic space was created that included Russia and Kazakhstan. One of the effective tools of improvement of competitiveness of developing economies under conditions of globalization is transborder clusters. Thus, a special interest goes to identification of spheres, into which the potential clusters of Russia and Kazakhstan in transborder regions could form. That is why, using the methodology of the European cluster observatory, we shall present in this article the evaluation of the spheres in which the formation of the clusters takes place. This would clarify the consequences of scenario of stable growth and integration of economies of neighboring countries into the single economic space. One of the discoveries of this article shows that statistical evaluations prove that economies of Kazakhstan and Russia are not ready for global expansion of regional competitiveness on the basis of cluster development; there is a significant asymmetry in the structure of spheres from the perspective of formation of transborder clusters.
\end{abstract}

Keywords: integration, transborder regions, Eurasian economic space, cluster, modern Russia.

\section{Introduction}

In 2015, the Internet Projects company conducted a poll, the results of which showed othat most of the respondents (77\%) consider Russia to be a Eurasian country that follows its own path of development. At that, $42 \%$ would prefer Russia's orientation at cooperation with its Asian neighbors and the "East" in general. And only $29 \%$ of the respondents wish for Russian to cooperate closer with countries of Europe and with the USA, and for closer integration with the "West".

The fact that clusters are tools of competitiveness of economy both in countries with developing economies and in countries with developed economies is recognized by many scientists. It is possible to present a variety of examples of transborder clusters in the USA, Canada, and countries of Western and Eastern Europe. Recently, the programs of clusters' support were adopted in Russia and Kazakhstan. As is well-known, the countries of the former Soviet Union are distinct for their attraction to paternalism - they are marked by (though, based on market principles) development from "above", not from "below". This means that programs and plans are often perceived as orientations, necessary for implementation.

The goal of this article is identification of the spheres, in which the potential transborder clusters in Russia and Kazakhstan might form in future. In order to achieve this purpose, it is necessary to do the following: determine the best methodology for identification of clusters, gather all necessary statistical data, and conduct empirical calculations and analysis of obtained results. The results of identification of perspective transborder clusters of Russia and Kazakhstan are very interesting for a wide circle of readers: researchers of regional and international processes in economy, representatives of public authorities which are indulged in the issues of development of regional economic policy and international cooperation. The article's conclusions as to tendencies in the formation of transborder clusters will be useful for the Russian and Kazakh entrepreneurs and businessmen of other countries which work or plan to work with the markets of Russia and Kazakhstan.

Russia and Kazakhstan's trade is very active. While in Russia most of the regions use the cluster technologies for 
the development, this process is only beginning in the regions of Kazakhstan. Therefore, main calculations will refer to regions of Kazakhstan.

Russia and Kazakhstan actively conduct the international trade between each other. It is obvious that transregional trade would have more volume in future if two neighboring regions with low barriers for mutual trade perform the complementary development, supplying scarce goods, products, and services. This traditional approach is described in the works of many scientists (e.g., Porter, 1986). The motivation for resource, merchandise, and informational exchange between regions is the presence of competitive advantages and difference of potentials. In the process of globalization, followed by lowering of barriers for exchange of resources and goods, a gradual aligning of potentials should be taking place. This is manifested in the fact that migration of cheap labor force to other territories may lead to its deficit and, consequently, to increase of payment for labor. However, that is not a usual state of affairs: instead of expected deletion of differences, they actually grow against the background of separatism, increase of interest towards self-identity and traditions of the country. The extreme variant of this situation - dissolution of the territories into several independent states (R. Robertson, 1992).

Despite the discussions, there remains an obvious fact that transregional trade of boundary regions grows within the frames of transborder clusters. Here the potential transport costs are the lowest ones, and the stable connections as to exchange of knowledge and competencies form under condition of open borders. The border is a very important factor of evolutionary path of transborder cooperation.

That is why it is very interesting to identify and compare the potential clusters in transborder regions of Kazakhstan and Russia.

\section{Local Development of Boundary Regions of Russia and Kazakhstan}

Kazakhstan has the longest common border with Russia and borders on the largest number of Russian regions. The common border with Russia constitutes more than 7,000 km. Twelve Russian regions (Astrakhan, Volgograd, Saratov, Samara, Orenburg, Chelyabinsk, Kurgan, Omsk, Tyumen, Novosibirsk Oblasts, Altai Krai, and the Republic of Altai) of four federal districts (Southern, Volga, Ural, and Siberian) have common borders with Kazakhstan.

GRP of Russian near-border regions reaches $20 \%$ of the Russian Federation's GDP and constitutes $40 \%$ of the Republic of Kazakhstan's GDP. From Russian side, in 12 near-border regions near Kazakhstan there live about 26 million people. From Kazakh side, in 7 regions, which border on Russia, there live 5.8 million people.

Kazakhstan is one of the closest allies of Russia. Thus, in 2013, the poll conducted by Levada-Center showed that Russian considers Kazakhstan the second (28\%) in the list of allies, after Belarus (34\%). The third place was taken by Germany (17\%), and the fourth - by China (16\%).

The close cooperation between Russia and Kazakhstan is supported by preservation of economic connections between enterprises, which have formed back in Soviet era, by favorable institutional conditions (law, the Customs Union, Common Economic Space), rational logistics, and absence of language barrier.

\section{Review of Literature and the Methodology}

Nowadays, the economists offer a variety of methods for identification (Table 1).

Table 1. Methods for clusters identification.

\begin{tabular}{|c|c|c|c|}
\hline Methods & Level of use/ object of research & Advantages & Disadvantages \\
\hline $\begin{array}{l}\text { Statistical (complex of special } \\
\text { indicators)* }\end{array}$ & Meso/ type of economic activity, sector & $\begin{array}{l}\text { Availability of statistics, } \\
\text { simplicity of calculation }\end{array}$ & Risk of getting the incomplete information \\
\hline Expert poll & Micro/ company & Adaptability, universalism & Labor intensity, verifiability \\
\hline $\begin{array}{l}\text { Multisectorial qualitative analysis } \\
\text { (MSQA) }\end{array}$ & Meso/ type of economic activity, sector & Simplicity of calculation & Risk of getting the incomplete information \\
\hline $\begin{array}{l}\text { "Costs-output" as to material flows } \\
\text { (IO) }\end{array}$ & $\begin{array}{l}\text { Meso, micro/ type of economic activity, } \\
\text { sector, company }\end{array}$ & Detailed data & Use of outdated information \\
\hline $\begin{array}{l}\text { Theory of graphs, network analysis } \\
\text { (NA) }\end{array}$ & $\begin{array}{l}\text { Meso, micro/ type of economic activity, } \\
\text { sector, company }\end{array}$ & Visualization & Abstraction \\
\hline Unclear sets & Meso/type of economic activity, sector & Flexibility & $\begin{array}{l}\text { Difficulty with collation of information and } \\
\text { justification of probability }\end{array}$ \\
\hline Correlation-regression analysis & $\begin{array}{l}\text { Meso, micro/ type of economic activity, } \\
\text { sector, company }\end{array}$ & Possibility for modifications & Risk of false connections \\
\hline
\end{tabular}

Compiled on the basis of the source (T.R. Gareev, 2012), *-added by the author 
At that, the identification of clusters remains one of the main problems of the cluster approach. As a rule, two basic approaches for clusters identification are discerned. The first approach of identification from "below" supposes the identification of the circle of cooperating enterprises which are combined on the basis of a single technological chain or technology. In this case, as a rule, the enterprises-leaders and members are already known; analysis of their cooperation allows building the network in the cluster (L.S. Markov, 2013). The significant drawbacks of this approach are labor intensity and closed nature of information from the side of enterprises. Most often this approach reveals an already existing large cluster: a big enterprise of the country's or region's sphere with a network of suppliers and contractors. As a rule, this enterprise's demand for personnel is already supplied by education establishments which train the qualified specialists.

When it comes to implicit clusters (so called "protoclusters"), which are probably at the stage of formation, the approach from "above" is used. This approach is based on the use of statistical methods of identification of specific types of activity, within which the spatial localization of industries takes place. A timely identification of these types of activities and industries is required for development of measures of advance nature for the formation of clusters.

The defining factors of clusters' effectiveness are possibilities for mutual use of technologies, infrastructure, and intellectual resources and knowledge, as well as demand. At that, M. Porter recommends to divide clusters into two types: trade and local. While local clusters serve only local markets, the trade clusters are oriented at serving the markets in other regions and countries. In this regard, the presence of trade clusters in the region might be an important factor of competitiveness and innovational development (M. Porter, 2003).

With that, the identification, like the further analysis of the cluster, is associated with a variety of problems: borders of the cluster (cluster localization), connections between the companies within the frames of mutual use of a single technology, technological interconnection of spheres (M. Porter, 2003).

Indeed, a significant problem, which hinders the realization of clusters as a tool of socio-economic development, is defining the borders of the clusters. This issue led to the appearance of the whole sphere - identification and cluster mapping.

The absence of unified approached to defining of clusters led to discussion about their classification.

T.R. Gareev, drawing upon generalization of a variety of works, including Porter's, recommends characterizing clusters through five "Cs":

- concentration (geographical) as a basis for formation of cluster on the territory;

- competition between companies, which facilitates the creation of dynamic network of internal suppliers;

- horizontal and vertical cooperation, ensuring the creation of specialized infrastructure around the cluster;

- communication, aimed at the promotion and formation of the cluster's brand;

- competence of labor resources of the cluster in the profile sphere of the cluster's activity on the given territory (T.R. Gareev, 2012).

The author notes that specifics of the above criteria cause methodological difficulties due to the vagueness of formulations and subjectivity of evaluations.

However, in our opinion, this matter is not limited by the terminology of the notion - it lies in its very sense. A cluster, as an open self-organizing system, is not limited by the territorial limits. Very often the cluster's borders do not coincide with administrative and territorial borders. Some specialists even think that it's impossible to determine the borders of a cluster (A.B. Drozdov, N.V. Drozdova, 2008). Another important condition is the fact that a cluster exists in a certain institutional environment which influences it directly. As the institutional environment in the countries with different types of economy differs substantially, this means that the path of cluster's development will be different in developing countries and countries with developed market economy. It is necessary to take into account the institutional features of clusters (A.E. Shastitko, 2009). The specific nature of clusters in a different economic system is proved by its institutional nature (T.R. Gareev, 2012).

That's why we agree with the statement that analysis of a cluster requires, besides statistical methods, the use of comparative analysis which takes into account the institutional nature of economic system, in which the cluster exists.

The necessity for consideration of influence of institutional environment was pointed out by L.S. Markov, who gives the following definition of a cluster: "a self-organizing system in economy, one of the most important parameters of which is the structure that is mutually dependent on the institutional environment" (L.S. Markov, 2014).

It is possible to discern two general approaches to the identification of a cluster: statistical and diagnosis of closeness of connections in a cluster by means of qualitative analysis. At the same time, it is possible to state that in the case of identification of protoclusters, the most effective is the statistical method - as the identification of economic ties between potential members is almost impossible due to their weakness or absence. The next important issue is the 
complex of estimated figures of the potential cluster.

Within the statistical approach it is necessary to calculate the figures which characterize the spheres with the largest proportion in the total volume of the region that shows a good dynamics of development and perspectives of trade with the external world. The European cluster observatory conducts the identification and analysis of clusters solely on the basis of statistical data about regions and spheres. The observation indicators are the following:

\subsection{General indicators}

- Employees - total number of employees in the sphere, people. Here it is necessary to evaluate the dynamics of the quantity of employees for the past 3 years.

- Number of enterprises in the sphere and the dynamics of this indicator for the past 3 years.

- Number of employees per enterprise in the sphere;

- Average wage at the enterprises of the sphere.

\subsection{Agglomeration}

- Observatory star rating - assigned (from 1 to 3 ) based in the agglomeration parameters. Maximal number of stars (3) is assigned if the cluster is inside the top ten in the given category as to the size, the level of specialization is no less than 2, and the cluster is inside the top ten as to the weight parameter. In this case, a star is assigned for each parameter.

- Size of the cluster - is estimated as a ratio of number of employees in the given cluster to the number of employees nation-wide.

- Specialization - according to recommendation of the European cluster observatory, it is determined as a ratio of the proportion of employees in the region's cluster to the proportion of employees in the similar sphere on the average in the country.

- Focus of the cluster in the region - ration of the number of employees in the cluster to the total number of employees in the region.

For the Russian practice, it is possible to calculate almost all of the above indicators, except for "number of enterprises" and "number of employees per enterprise".

In American practice, statistical indicators, including the ones for estimation of connection with related spheres, are used.

Developing his own approaches to the identification and analysis of a cluster, in $2014 \mathrm{M}$. Porter and his colleagues from Harvard Business School, M. Delgado and C. Stern, offered to pay more attention to evaluation of connection to other related spheres, because the trade cluster, as a driver of regional development, creates a basis for development of subsets of local clusters (educational, medical, etc.) (M. Porter, M. Delgado, C. Stern). As a rule, the trade clusters are presented by a group of related spheres, connected by a high level of qualification, by technologies, offer, demand, and other possible connections. In 2014, Delgado, R. Bryden, and S. Zyontz grouped 778 spheres into 51 clusters in the USA (M. Delgado, R. Bryden, S. Zyontz, 2014). The authors of the research noted that trade and local clusters, despite their difference, are complementary to each other. Trade clusters feature less employees than local clusters, but trade clusters are "responsible" as a driver of development of the region by means of creation of innovational production and provision of larger wages. According to 2009 data, the trade clusters in the USA provided $36 \%$ of the number of employed population and $91.2 \%$ of the total number of patents (Table 2 ).

Table 2. Comparison of trade and local clusters in the USA, 2009 (\%)

\begin{tabular}{ccc}
\hline & Clusters & \\
& Trade & Local \\
\hline Employment & 36 & 64 \\
Volume of sales & 50.5 & 49.5 \\
Patents & 91.2 & 0.5 \\
\hline
\end{tabular}

Source: Delgado M., Bryden R., Zyontz S. Categorization of Traded and Local Industries in the US Economy.

Complementarity of trade and local clusters can to the fullest extent be seen on the basis of the analysis of employment 
indicators, as the trade and local clusters create demand for certain professions.

Let us discern the criteria for cluster identification:

1. The sphere has $50 \%$ and more enterprises with average of 10 employees. This criterion allows discerning regions with a vivid structure, in which the most of the enterprises are small.

2. The second criterion allows discerning the second case and determining the clusters with a coefficient of employment in the sphere is $25 \%$ and more. This criterion allows determining regions and sphere with a high level of concentration and specialization.

3. The third, and last, criterion is used for evaluation of the level of differentiation between the coefficient of localization with $90 \%$ and the coefficient of localization with median that exceeds 1.5 for this sphere. This criterion allows covering the spheres with a high level of differentiation of localization coefficient, but low concentration. According to the authors (M. Delgado, R. Bryden, S. Zyontz, 2014), this criterion helps to identify the trading activity in the spheres which in the current state cannot be referred to trade or local clusters.

In the classical theory of clusters, the geographic borders are one of the basic characteristics - still, it is difficult to determine them. However, there are researchers who deny this condition and, what is more, declare the problem of excessive closeness. Thus, R. Boshma considers that, together with insufficient closeness, there might be issues of excessive closeness which hinder the appearance of innovations (R. Boshma, 2005). Geographic proximity of economic entities has an essential meaning for local clusters - but not for trade clusters, as the first type is connected to the territory, while the second type may include members which are situated behind the limits of administrative and territorial boundaries.

In regard of cooperation of Kazakhstan's regions, the general idea of this article is presented in Figure 1 and consists in the fact that under conditions of creation of the Eurasian Economic Community, the competitiveness of Russia's and Kazakhstan's economies will be increased by formation of transborder clusters:

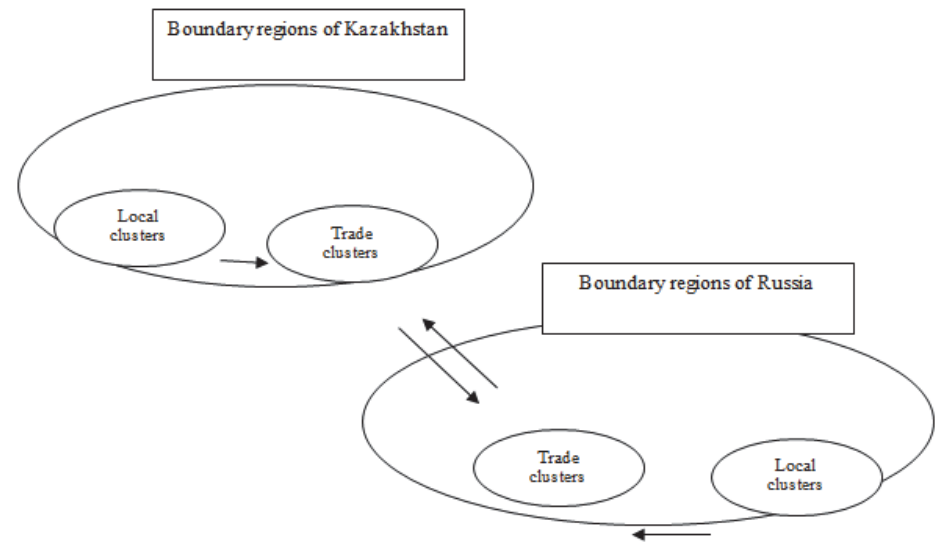

Figure 1. Scheme of cooperation of boundary regions under the conditions of clusters' development

At that, trade clusters are drivers of international trade, and local clusters serve the boundary regions of Russia and Kazakhstan. As was mentioned above, the modern practice of cluster identification uses, as a rule, diagnosing of the closeness of connections in a cluster by means of qualitative analysis or statistical method. In our case, it is impossible to use the first method, as clusters in Kazakhstan - in modern market understanding - are at the initial stages, and cluster policy is at the initial stage of development and implementation. That's why we chose the statistical method.

While using the statistical method for identification of clusters, the main issue is the content of indicators. Generalization of methodological approaches allows concluding that for identification of potential clusters in Kazakhstan, it is advisable to use the complex of the following statistical indicators:

1. Employees - total number of employees in the sphere, pax. Here it is necessary to evaluate the dynamics of the quantity of employees for the past 3 years.

2. Number of enterprises in the sphere, and the dynamics of this indicator for the past 3 years.

3. Number of employees per enterprise in the sphere. 
4. Average wage at the enterprises if the sphere;

5. Size of the cluster - is estimated as a ratio of number of employees in the given cluster to the number of employees nation-wide.

6. Specialization - according to recommendation of the European cluster observatory, it is determined as a ratio of the proportion of employees in the region's cluster to the proportion of employees in the similar sphere on the average in the country.

7. Focus of the cluster in the region - ration of the number of employees in the cluster to the total number of employees in the region. This indicator is important for determining the weight of the given sphere in the region's economy.

For the identification of the cluster type (in M. Porter's terminology), let us supplement the complex of indicator with the following criteria:

The average number of 30 employees at an enterprise shows that the sphere includes mainly small enterprises and characterizes the potential cluster as a local one.

The coefficient of employment on the sphere equals $25 \%$ and more; it shows the high specialization in the region within one, or rarely two, central clusters - which could have a role of a trade cluster for the region.

The choice of the statistical method of clusters identification and the above mentioned indicators is reasoned by the following:

Firstly, official statistical offices in Kazakhstan (Statistic agency of the Republic of Kazakhstan) conduct the gathering of all information, required for the calculation.

Secondly, the given indicators, offered by the scientists of Stockholm School of Economics, recommended themselves and are widely used at present time for the identification and further monitoring of the clusters by the European cluster observatory, covering the countries of Europe. The results of the calculations might be used for the comparative analysis as to similar indicators ${ }^{1}$

Thirdly the presented complex of criteria and indicators is enough for identification of clusters and their type.

\section{Types and Sources of Data}

For the identification of potential clusters in Kazakhstan, the following public data of official statistic offices were used: Committee on statistics of Kazakhstan, regional Departments of statistics. The research covers the following regions: West Kazakhstan Region (WK), East Kazakhstan Region (EK), Atyrau Region (AT), Kostanay Region (KO), Aktobe Region (AK), Pavlodar Region (PA), North Kazakhstan Region (NK) for the period of 2010-2013. As the emphasis was put on the study of potential clusters of local development of Kazakhstan's regions, the gathered data was divided into fourteen main sectors: Agriculture, forestry, and fish industry (AGR), Minerals industry and quarry development (MI), Manufacturing industry (MAI), Building (BU), Wholesale and retail trade, consumer services (WRT), Transport and logistics (TL), Services on accommodation and meals (SAM), Information and connection (IC), Financial and insurance activities (FI), Operations with real estate (RE), Professional, scientific, and technical activities (PST), Education (ED), Healthcare and social services (HCC), Art, entertainment, and rest (AER). These spheres correspond to the official document General classifier of types of economic activity (Civil Code of the Republic of Kazakhstan 03-2007), which allows providing a single approach and discerning the potential spheres for the formation of a cluster. Of all the spheres, the most coverage is provided by Minerals industry and quarry development (MI) and Manufacturing industry (MAI). Thus, MI sphere includes extraction of minerals as well as supplementary types of activities for the purpose of preparation of raw material for realization. Similarly, the Manufacturing industry (MAI) covers the spheres of industry and manufacture of any products - from oil processing to food products. The data on clusters of regions of Russia that border on Kazakhstan, are a generalization of official government data, presented in the strategies and programs of regional development, and on the official sites of regional authorities. The results of the calculations will be the basis for the further specification and identification of specific clusters.

\section{Empirical Results and Analysis}

Tables 1 and 2 of Appendix A shows the dynamics of quantity of employees and dynamics of quantity of enterprises in boundary regions of Kazakhstan.

Quantity of employed in the Agriculture (AGR) reduces rapidly in all boundary regions of Kazakhstan, while the

${ }_{1}^{1}$ Preserving the comparability as to indicator of average wages, which is calculated in EUR in the European cluster observatory. 
quantity of enterprises remains the same or increases, which proves the outflow of labor resources from this sphere and reduction of sizes of enterprises.

From the perspective of formation of potential clusters, the most interesting are the spheres with the highest rates of growth of employee number and good dynamics of enterprises' quantity.

In the Minerals industry and quarry development (MI) sphere, the highest rates of employees number growth are observed in Pavlodar Region - given that in 2013 there were 20,000 employees in this sphere. Among the boundary regions, the highest number of employees at the enterprises of minerals industry is observed in East Kazakhstan Region; still, here the increase of the quantity of enterprises is observed, as well as of the quantity of employees.

The leadership as to the quantity of employees in Manufacturing industry (MAl) belongs to Pavlodar region 97,000 people. At that, the quantity of employees used to be stable, and only in 2013 there was an increase of the number of employees by $4 \%$. The number of enterprises, on the contrary, reduced by $2 \%$ after the previous growth in 2011 and 2012.

In all boundary regions of Kazakhstan, the dynamic growth of quantity of employees and enterprises is peculiar for Education industry (ED). That is a positive sign, as this is the sphere where the basis of potential for knowledge, skills, and experience of the employees is established.

In Table 2, the results of calculation of clusters' size are presented.

Table 2. Cluster size

\begin{tabular}{cccccccc}
\hline & WK & EK & AT & KO & AK & PA & NK \\
\cline { 2 - 7 } Size of the region as to the labor potential & 0.037 & 0.083 & 0.033 & 0.059 & 0.048 & 0.049 & 0.038 \\
\hline AGR & 0.039 & 0.087 & 0.006 & 0.091 & 0.027 & 0.045 & 0.068 \\
MI & 0.024 & 0.089 & 0.063 & 0.111 & 0.122 & 0.079 & 0.003 \\
MAI & 0.024 & 0.124 & 0.031 & 0.043 & 0.043 & 0.176 & 0.025 \\
BU & 0.039 & 0.063 & 0.066 & 0.026 & 0.049 & 0.018 & 0.010 \\
WRT & 0.032 & 0.077 & 0.022 & 0.070 & 0.062 & 0.038 & 0.029 \\
TL & 0.028 & 0.077 & 0.049 & 0.045 & 0.066 & 0.052 & 0.037 \\
SAM & 0.027 & 0.078 & 0.052 & 0.021 & 0.038 & 0.011 & 0.025 \\
IC & 0.031 & 0.049 & 0.039 & 0.046 & 0.044 & 0.086 & 0.023 \\
FI & 0.036 & 0.055 & 0.035 & 0.026 & 0.044 & 0.093 & 0.022 \\
RE & 0.039 & 0.094 & 0.040 & 0.069 & 0.057 & 0.014 & 0.031 \\
PST & 0.038 & 0.088 & 0.085 & 0.029 & 0.055 & 0.063 & 0.018 \\
ED & 0.241 & 0.076 & 0.035 & 0.046 & 0.054 & 0.043 & 0.042 \\
HCC & 0.021 & 0.093 & 0.028 & 0.048 & 0.039 & 0.060 & 0.035 \\
AER & 0.015 & 0.084 & 0.035 & 0.042 & 0.037 & 0.116 & 0.031 \\
\hline
\end{tabular}

The first table entry shows the size of the region as to the labor potential. The largest boundary regions as to the labor potential are East Kazakhstan and Kostanay Regions, having 8,3\% and 5,9\% shared, respectively. The scale of other boundary regions does not exceed the share of $5 \%$.

The regions with developed Manufacturing industry (MAl) are East Kazakhstan and Pavlodar Regions. The size of the MAI cluster in East Kazakhstan Region is 0.124, in Pavlodar Region - 0.176. East Kazakhstan Region is situated in the north-east of the republic. The region borders on the Russian Federation and the People's Republic of China. The leading sphere in the region's industry is black metallurgy, the share of which in the total potential of the region constitutes about $55 \%$ and which is almost completely exported. The spheres of machine building and metal processing, forestry and wood processing, light and food industry are also rather developed. The leading sphere of Pavlodar Region which provides more than $70 \%$ of the manufacture industry production is metallurgy and metal processing. A significant place in the economy of Pavlodar region belongs to Minerals industry and quarry development (MI) -0.079 .

The size of the Ml cluster is rather high -0.111 - in Kostanay Region and Aktobe region -0.122 . The size of the ED clusters in West Kazakhstan Region - 0.241 and AER clusters in Pavlodar Region - 0.116 - should also be noted.

Table 3 shows the results of calculation of specialization of boundary regions of Kazakhstan. 
Table 3. Specialization of boundary regions.

\begin{tabular}{cccccccc}
\hline & WK & EK & AT & KO & AK & PA & NK \\
\hline AGR & 1.058 & 1.049 & 0.176 & 1.554 & 0.560 & 0.914 & 1.782 \\
MI & 0.641 & 1.073 & 1.945 & 1.890 & 2.532 & 1.618 & 0.072 \\
MAI & 0.652 & 1.502 & 0.939 & 0.730 & 0.894 & 3.612 & 0.657 \\
BU & 1.059 & 0.761 & 2.032 & 0.438 & 1.019 & 0.360 & 0.268 \\
WRT & 0.866 & 0.928 & 0.667 & 1.196 & 1.283 & 0.780 & 0.747 \\
TL & 0.771 & 0.934 & 1.509 & 0.771 & 1.376 & 1.067 & 0.963 \\
SAM & 0.740 & 0.940 & 1.594 & 0.355 & 0.792 & 0.223 & 0.663 \\
IC & 0.835 & 0.592 & 1.206 & 0.781 & 0.906 & 1.771 & 0.598 \\
FI & 0.979 & 0.665 & 1.061 & 0.443 & 0.916 & 1.906 & 0.574 \\
RE & 1.055 & 1.139 & 1.239 & 1.181 & 1.184 & 0.279 & 0.818 \\
PST & 1.040 & 1.069 & 2.607 & 0.495 & 1.140 & 1.288 & 0.456 \\
ED & 6.538 & 0.923 & 1.063 & 0.776 & 1.118 & 0.881 & 1.104 \\
HCC & 0.563 & 1.125 & 0.871 & 0.809 & 0.816 & 1.223 & 0.906 \\
AER & 0.414 & 1.014 & 1.066 & 0.713 & 0.774 & 2.376 & 0.817 \\
\hline
\end{tabular}

High values of sectorial specialization of regions are observed in West Kazakhstan Region in the ED cluster (6.538), in Pavlodar Region in the MAI (3.612) and AER clusters (2.376), in Atyrau Region in the PST cluster (2.607) and in Aktobe Region in the MI cluster (2.532).

Table 4 shows the evaluation of clusters' focus in boundary regions of Kazakhstan.

Table 4. Focus of the cluster in the region.

\begin{tabular}{cccccccc}
\hline & WK & EK & AT & KO & AK & PA & NK \\
\hline AGR & 25.592 & 25.388 & 4.258 & 37.602 & 13.545 & 22.107 & 43.112 \\
MI & 1.864 & 3.121 & 5.660 & 5.499 & 7.366 & 4.707 & 0.210 \\
MAI & 4.171 & 9.602 & 6.002 & 4.665 & 5.718 & 23.092 & 4.199 \\
BU & 8.152 & 5.860 & 15.645 & 3.375 & 7.851 & 2.771 & 2.062 \\
WRT & 12.701 & 13.598 & 9.775 & 17.530 & 18.803 & 11.436 & 10.951 \\
TL & 5.118 & 6.199 & 10.017 & 5.122 & 9.135 & 7.082 & 6.394 \\
SAM & 1.201 & 1.525 & 2.585 & 0.576 & 1.284 & 0.362 & 1.075 \\
IC & 1.295 & 0.918 & 1.871 & 1.211 & 1.405 & 2.747 & 0.927 \\
FI & 1.580 & 1.073 & 1.712 & 0.715 & 1.478 & 3.077 & 0.926 \\
RE & 1.295 & 1.398 & 1.521 & 1.449 & 1.454 & 0.343 & 1.005 \\
PST & 2.212 & 2.273 & 5.543 & 1.052 & 2.423 & 2.738 & 0.970 \\
ED & 13.902 & 9.941 & 11.450 & 8.358 & 12.043 & 9.495 & 11.887 \\
HCC & 6.066 & 5.578 & 4.317 & 4.010 & 4.047 & 6.061 & 4.491 \\
AER & 2.054 & 1.271 & 1.335 & 0.893 & 0.969 & 2.977 & 1.024 \\
\hline
\end{tabular}

The cluster's focus in the region, which is calculated as a ratio of cluster's employees to the total employees in the region, characterizes the weight of the given sphere in the region's economy.

The data of Table 3 shows that in many boundary regions, most of the population is concentrated in the agricultural sphere. The AGR cluster has a large weight in North Kazakhstan Region (43.112), Kostanay Region (37.602), West Kazakhstan Region (25.592), East Kazakhstan Region (25.388), and Pavlodar Region (22.107).

Table 5 shows the spheres in boundary regions of Kazakhstan, in which the average number of employees at enterprises is less than 30 . 
Table 5. Average number of employees at enterprises is less than 30.

\begin{tabular}{cccccccc}
\hline & WK & EK & AT & KO & AK & PA & NK \\
\hline AGR & $>30$ & $>30$ & $>30$ & $>30$ & $>30$ & $>30$ & $>30$ \\
MI & $>30$ & $>30$ & $>30$ & $>30$ & $>30$ & $>30$ & 13 \\
MAI & $>30$ & $>30$ & 17 & 28 & $>30$ & $>30$ & 29 \\
BU & 22 & 20 & 12 & 14 & 15 & 7 & 11 \\
WRT & 21 & 15 & $>30$ & 22 & 18 & 11 & 15 \\
TL & $>30$ & $>30$ & $>30$ & $>30$ & $>30$ & $>30$ & $>30$ \\
SAM & $>30$ & $>30$ & 29 & $>30$ & $>30$ & 12 & $>30$ \\
IC & $>30$ & 25 & 27 & 28 & $>30$ & $>30$ & $>30$ \\
FI & 6 & 13 & 11 & 11 & $>30$ & $>30$ & 9 \\
RE & 9 & 7 & 22 & 13 & 11 & 2 & 4 \\
PST & 16 & 16 & $>30$ & 8 & 14 & 18 & 11 \\
ED & $>30$ & $>30$ & $>30$ & $>30$ & $>30$ & $>30$ & $>30$ \\
HCC & $>30$ & $>30$ & 16 & $>30$ & $>30$ & $>30$ & $>30$ \\
AER & $>30$ & $>30$ & 2 & $>30$ & 25 & $>30$ & 20 \\
\hline
\end{tabular}

Analyzing the data from the table, it should be noted that boundary regions of Kazakhstan feature a typical situation, when small enterprises are concentrated mostly in the sectors of the service sphere, and their joint activity is a basis for the formation of service protoclusters. The industry spheres are presented by small enterprises only in several regions with clear agricultural specialization. In North Kazakhstan Region - minerals industry and quarry development. In Atyrau, Kostanay, and North Kazakhstan Regions - manufacture industry.

A coefficient of employment of $25 \%$ and more was mentioned above as yet another important criterion, which shows a high level of specialization on the region within one, or less often, two central clusters. Such clusters, according to the specialists of M. Porter's school, may become the trade clusters for the region. As Table 3 shows, this criterion is fulfilled only in Agricultural industry (AGR) in West Kazakhstan (25.6\%), East Kazakhstan (25.4\%), Kostanay (37.6\%), and North Kazakhstan Regions (43.1\%).

\section{Conclusions and Consequences for the Policy}

The conducted calculations showed that only the clusters of the agricultural sphere correspond to all necessary criteria of traded clusters in West Kazakhstan, East Kazakhstan, Kostanay, and North Kazakhstan Regions. The potential protoclusters with good perspectives are production of oil-refining products and metallurgy.

However, in order to make the conclusions and evaluate the consequences for the policy of boundary regions, it is necessary to supplement the conducted analysis with the information regarding the clusters which already exist or are at the stage of formation in boundary regions of Russia and to compare them with Kazakhstan's protoclusters.

Figure 2 shows the clusters of boundary regions of Russia and Kazakhstan. In some boundary regions of Russia and Kazakhstan there are signs of development of the clusters of one sphere. 


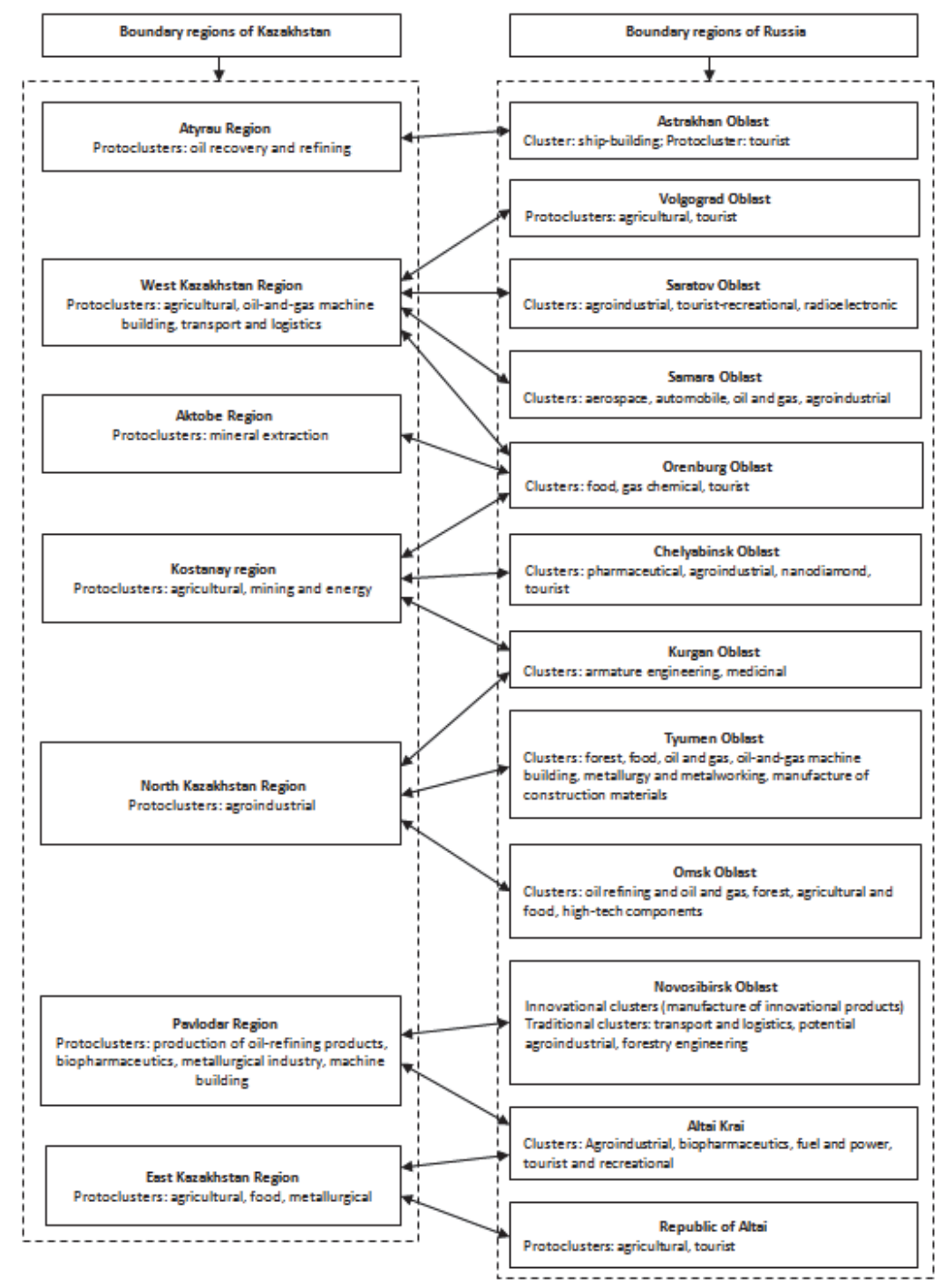

Figure 2. Clusters of boundary regions of Russia and Kazakhstan.

The governments of Russia and Kazakhstan should take that into account and, under condition of common economic space, prepare the measures for the improvement of cluster initiatives of development of cooperation as to formation of transborder clusters. Thus, it is advisable to develop transborder agricultural clusters from the Russian side in Altai Krai, Republic of Altai, Chelyabinsk, Omsk, Orenburg, Saratov, Samara, and Volgograd Oblasts, and from Kazakhstan side in East Kazakhstan, Kostanay, North Kazakhstan, and West Kazakhstan Regions.

\section{References}

Gareev, T. R., 2012. Clusters in institutional plane: theory and methodology of local socioeconomic development. Baltic region. (3):7-33. URL: http://journals.kantiana.ru/upload/iblock/a19/cijjlozjjpoap_7-33.pdf (Accessed on January 15, 2015)

Service of online queries FoxRu.Net, n.d. Globalization: pros and cons. URL: http://www.voxru.net/?source=subscribe (Accessed on January 15,2015$)$ 
Drozdov, A. B., Drozdova, N.V. 2008. Approaches to modeling of economic systems. Modeling and analysis of informational systems. 15 (1):51-62. (Accessed on January 15, 2015)

Markov, L. S., et. al., 2013. Cluster policies and initiatives: theory, methodology, practice. Y. S. Artamonova and B. B. Khrustalev (Eds.). Tugushev S. Y., Penza. ISBN: 978-5-904470-26-6, pp: 230.

Markov, L. S. 2014. Theoretical and methodological basis for cluster approach in economics. Extended abstract of Doctor's thesis. Novosibirsk. URL: http://simulation.su/uploads/files/default/2014-abstract-doc-markov.pdf (Accessed on January 11, 2015).

Shastitko, A. E., 2009. Clusters as a form of spatial organization of economic activity: theory of the issue and empirical observations. Baltic region. (2):9-32. (Accessed on January 9, 2015).

Bergman, E., and Feser, E., 1999. Industrial and regional clusters: concepts and comparative applications. S. Loveridge, (ed.). Regional Research Institute, West Virginia University, Morgantown. URL: http://rri.wvu.edu/WebBook/Bergman-Feser/contents.htm (Accessed on January 10, 2015).

Boschma, R., 2005. Proximity and innovation: a critical assessment. Regional Studies, 39 (1):61-74. DOI: 10.1080/0034340052000320 887

Broek, J. and Smulders, H., (2013). The evolution of a cross-border regional innovation system: An institutional perspective. Regional Studies Association European Conference, Tampere. URL: http://www.regionalstudies.org/uploads/Van_Den_Broek_Smulders. pdf (Accessed on January 9, 2015).

Delgado M., Bryden R., and Zyontz S., n.d. Categorization of Traded and Local Industries in the US Economy. Official page of interactive cluster project of Harvard Business School. URL: http://www.clustermapping.us/sites/default/files/files/page/Categorization\% 20of\%20Traded\%20and\%20Local\%20Industries\%20in\%20the\%20US\%20Economy.pdf (Accessed on January 13, 2015).

Delgado, Mercedes, Porter, Michael E., and Stern, Scott, 2014. Clusters, Convergence, and Economic Performance. Research Policy, 43 (10):1785-1799. DOI: 10.1016/j.respol.2014.05.007

Desrochers, Pierre and Sautet, Frédéric, 2004. Cluster-Based Economic Strategy, Facilitation Policy and the Market Process. Review of Austrian Economics, 17 (2-3):233-245. URL: http://www.gmu.edu/depts/rae/archives/VOL17_2-3_2004/6_Desrochers.pdf (Accessed on January 13, 2015).

Krugman, P. R. and Obstfeld, M., 2012. International Economics: Theory and Policy. 9th Ed. Addison-Wesley, Massachusetts. ISBN-13: 978-0-13-214665-4; ISBN-10: 0-13-214665-7, pp: 736.

Porter, M. E., (ed.), 1986. Competition in Global Industries. Harvard Business School Press, Boston.

Porter, Michael E., 2003.The Economic Performance of Regions. Regional Studies, 37 (6-7):549-578. DOI: 10.1080/0034340032 000108688.

Porter, Michael E., 1998. Competitive Advantage of Nations. 2nd Ed. Free Press, New York. ISBN: 978-0-684-84147-2, pp: 896. 